\title{
EFEITO DA SEMEADURA A LANÇO E DA POPULAÇÃO DE PLANTAS NO RENDIMENTO DE GRÃOS E OUTRAS CARACTERÍSTICAS DA SOJA [Glycine max (L.) Merrill]
}

\author{
Effect of broadcast seeding and plant density in the grains \\ yield and other characteristics of soybean [Glycine Max (L.) Merrill] \\ Pedro Milanez de Rezende ${ }^{1}$, Cristiane Fortes Gris ${ }^{2}$, Leonardo Lino Gomes ${ }^{2}$, \\ Maria Cristina Cavalheiro Tourino ${ }^{3}$, Élberis Pereira Botrel ${ }^{3}$
}

\begin{abstract}
RESUMO
A busca de novas alternativas no sentido de aumentar a produtividade da cultura da soja tem sido o objetivo de vários pesquisadores. Com esse intuito, conduziu-se, num Latossolo Vermelho Escuro da Fazenda Canadá, em Jussara (GO), um ensaio utilizando sistema de semeadura (lanço e sulco) e populações de plantas (200, 300, 400, 500, 600 e 700 mil plantas.ha $^{-1}$ ), com delineamento de blocos ao acaso em esquema fatorial $(2 \times 6)$, com três repetições. No sistema de semeadura em sulcos, as parcelas foram constituídas de 4 linhas, espaçadas de $50 \mathrm{~cm}$, com área útil de $4,0 \mathrm{~m}^{2}$; mesma área útil foi utilizada para o sistema de semeadura a lanço. A semeadura a lanço proporcionou aumento no rendimento de grãos de 35,33\% $\left(1.128 \mathrm{~kg} . \mathrm{ha}^{-1}\right)$, em comparação com o sistema em sulcos. As diferentes populações alteraram significativamente o rendimento de grãos, com destaque para a de 400.000 plantas.ha ${ }^{-1}$, que apresentou também o menor índice de acamamento.
\end{abstract}

Termos para indexação: Soja, semeadura, lanço, sulco.

\section{ABSTRACT}

The search of new alternatives in the sense of increasing the soybean productivity has been several research objective. With that intection, a trial was conduced at the farmer Canadá, in Jussara (GO), in a Dark Red Latosol soil, utilized two sowing systems (broacast and furrows), plants populations $\left(200,300,400,500,600\right.$ and 700.000 plants.ha ${ }^{-1}$ ) in blocks casualized design with tree replications and factorial scheme (2x6). The portion were constituted of 4 row spacing of $0,50 \mathrm{~m}$ with useful area of $4,0 \mathrm{~m}^{2}$ in the system of sowing in furrows same area for the broadcast system. The use of the sowing broadcast system it provided increase in the grains yields of 35,33\% $\left(1128 \mathrm{~kg} \cdot \mathrm{ha}^{-1}\right)$ in comparison with of the furrow. The populations altered yield grains significantly with prominence for 4000.000 plants.ha $^{-1}$ wich presented also logding smaller.

Index terms: Soybean, sowing, broadcast, furrow.

(Recebido para publicação em 28 de julho de 2003 e aprovado em 30 de setembro de 2004)

\section{INTRODUÇÃO E REVISÃO DE LITERATURA}

A sojicultura brasileira está inserida em um mercado extremamente competitivo, e no contexto nacional exerce papel fundamental na busca de recursos para o País, por meio das exportações. Assim como em outros setores produtivos, o momento vivenciado na agricultura é caracterizado pela tentativa de otimização dos recursos de produção. O empresário sojicultor deve conhecer detalhadamente as suas despesas, devendo alocar com alto grau de certeza os recursos disponíveis no seu empreendimento, obtendo, assim, melhores resultados econômicos, considerando todo e qualquer fator que possa aumentar o nível de produtividade de sua lavoura. Visando a atingir esse objetivo, pesquisadores têm lançado mão de várias alternativas, como aumento da eficiência da adubação, determinação de melhor época de semeadura, escolha de melhores cultivares, utilização de estirpes de Rhizobium mais eficientes etc., sem, no entanto, preocuparem-se com os sistemas possíveis de semeadura.

No sistema de semeadura convencional, com o espaçamento e a densidade adequada, visa-se a aumentar o rendimento da cultura. Entre as várias maneiras disponíveis de ultrapassar as barreiras que limitam a obtenção dos mais altos rendimentos, o aumento da taxa de assimilação de $\mathrm{CO}_{2}$ nas folhas, obtida pela manipulação do microambiente mediante práticas culturais, constitui uma das maneiras mais fáceis para se atingir esse objetivo.

A variação na densidade e no espaçamento proporciona uma maior ou menor penetração da luz no

\footnotetext{
1. Engenheiro Agrônomo, Dr., Professor Titular do Departamento de Agricultura da Universidade Federal de Lavras/UFLA - Caixa Postal 37 - $37200-000$ - Lavras

MG.pmrezend@ufla.br (Bolsista do CNPq)

2. Mestrandos de Agronomia - Fitotecnia da UFLA

3. Professores Substitutos da UFLA.
} 
dossel das plantas. Uma melhor distribuição de luz poderia ser conseguida com um melhor arranjo das plantas, proporcionando às folhas inferiores maior iluminação, podendo, assim, contribuir de forma mais ativa no processo de fotossíntese. A área foliar sobre uma determinada área do solo, denominada índice de área foliar (IAF), é fator importante de produtividade da cultura. O valor correspondente a $95 \%$ de absorção da radiação incidente é chamado IAF "crítico", índice esse dependente da intensidade luminosa e também do número de plantas por área, ou seja, da densidade das plantas na fileira e da distância entre as fileiras (BARNI e BERGAMASCHI, 1981).

Nesse sentido, a lógica leva a pensar que a utilização de semeadura a lanço poderia proporcionar uma melhor distribuição das plantas na área, facilitando, assim, a penetração da luz, repercutindo, consequientemente, em aumento da produtividade. Levando-se em conta uma condição em que a água e os nutrientes encontrem-se presentes em quantidades suficientes, de modo que não haja competição em relação a esses fatores, a luz torna-se o fator limitante para a produção.

A esse respeito, Brandão (1968), utilizando a semeadura de arroz a lanço em solo seco no Rio Grande do Sul, espalhando as sementes no solo por meio de distribuidores portáteis, com posterior incorporação superficial ao solo com grade niveladora, mostrou que, quando não se tem o cuidado necessário no preparo do solo, muitas dessas sementes caem em fendas, mais profundas, com prejuízo para a emergência das plântulas, e outras permanecem na superfície, após a passagem da grade, secando antes mesmo de germinar. Para contrabalançar essas falhas, utiliza-se quantidade de sementes maior que a utilizada no plantio em fileira ou convencional. É importante, ainda, ressaltar que a semeadura a lanço impossibilita a eliminação mecânica de plantas daninhas, assim como a aplicação parcelada de fertilizantes no solo. Em estudo semelhante, verificou-se que a semeadura a lanço de arroz provoca desigualdade de população, havendo concentrações de população excessivas em determinadas faixas do terreno, com desuniformidade na emergência, no perfilhamento e na maturação (PEDROSO, 1987).

Trabalhos com plantio a lanço na cultura da soja são raros. Por meio de estudos realizados no Triângulo Mineiro utilizando a cultivar Paraná em semeadura convencional, no sulco e a lanço, com diferentes populações (111.500, 214.250, 274.500, 379.625, $411.375 \mathrm{e}$ 537.750 plantas. ha $^{-1}$ ), equivalentes a $75,100,125,154$, 175 e $200 \mathrm{~kg} \cdot \mathrm{ha}^{-1}$ de sementes, constatou-se que a se- meadura a lanço utilizando as três últimas quantidades de sementes superou a semeadura convencional com a utilização de $90 \mathrm{~kg} \cdot \mathrm{ha}^{-1}$ em $36 \%$ (600 kg.ha $\left.{ }^{-1}\right), 41 \%$ $\left(675 \mathrm{~kg} \cdot \mathrm{ha}^{-1}\right)$ e $64 \%$ (1.069 kg.ha $\left.{ }^{-1}\right)$, proporcionando, ainda, redução na infestação de plantas daninhas de $19,55 \%$ na semeadura tradicional para 10,$9 ; 11,72 \mathrm{e}$ $8,13 \%$, respectivamente, na semeadura a lanço (GUIMARÃES e ARANTES, 1979).

A soja possui a característica peculiar de manter uma determinada estabilidade de rendimento diante da variação na população de plantas, dentro de limites relativamente amplos. Essa estabilidade é proporcionada pela interdependência dos fatores componentes do rendimento. Em condições de baixa densidade populacional, o rendimento tende a se manter estável devido ao aumento de ramificações laterais, fato que pode ser aplicado pela alteração na intensidade de competição das plantas, em função das variações da população e da disponibilidade ambiental, para cada planta. A esse respeito, em pesquisa utilizando três populações (240, 450 e $570 . \mathrm{mil}$ plantas.ha ${ }^{-1}$ ) em sistema de semeadura a lanço, constatou-se que não ocorreu diferença significativa entre as diferentes populações, com rendimentos de grãos de $2.343,2.682$ e $2.675 \mathrm{~kg} \cdot \mathrm{ha}^{-1}$, respectivamente (SILVEIRA et al., 1983). De acordo com os autores, pelos níveis de produtividade alcançados, assume-se como válida a tecnologia proposta, uma vez que a operação de plantio a lanço é mais fácil de ser executada, quando comparada à tradicional, embora apresente um maior consumo de sementes.

Dada a necessidade de se procurar aumentar a produtividade da soja com a adoção de tecnologias, com o presente trabalho tem-se por objetivo avaliar a produtividade e outras características agronômicas da cultura, em função das semeaduras a lanço e tradicional, em diferentes populações de plantas.

\section{MATERIAL E MÉTODOS}

O experimento foi instalado na Fazenda Canadá, em Jussara (GO), em solo classificado com Latossolo Vermelho-Escuro, em 20/11/91, utilizando-se a cultivar Doko. A amostra de solo foi coletada na camada de 0 $20 \mathrm{~cm}$ de profundidade, apresentando as seguintes características químicas: $\mathrm{pH}$ em água $=5,0, \mathrm{P}=2$ $\mathrm{mg} / \mathrm{dm}^{3}, \mathrm{~K}=105 \mathrm{mg} / \mathrm{dm}^{3}, \mathrm{Ca}=1,0 \mathrm{cmolc} / \mathrm{dm}^{3}, \mathrm{Mg}=$ $0,9 \mathrm{cmolc} / \mathrm{dm}^{3}, \mathrm{Al}=0,5 \mathrm{cmolc} / \mathrm{dm}^{3}$, matéria orgânica $=$ $23 \mathrm{dag} / \mathrm{dm}^{3}$ e texturais: areia $=74 \%$, limo $=15 \%$ e argila $11 \%$. 
O delineamento experimental utilizado foi o de blocos ao acaso em esquema fatorial $(2 \times 6)$, compreendendo dois sistemas de semeadura (lanço e sulco) e seis populações $(200,300,400,500,600$ e 700 mil plantas.ha $\left.{ }^{-1}\right)$, com três repetições, correspondendo a um gasto de sementes de, respectivamente, 35, 52, 70, 87, 105 e $122 \mathrm{~kg} \cdot \mathrm{ha}^{-1}$, para semeadura no sulco. No caso do plantio a lanço, esses valores podem atingir um aumento de até $100 \%$ em relação ao gasto no convencional.

No sistema de semeadura no sulco, as parcelas foram constituídas de quatro fileiras de $5,0 \mathrm{~m}$ e espaçadas de $0,5 \mathrm{~m}$, sendo retiradas, a título de bordadura, duas fileiras externas e $0,5 \mathrm{~m}$ de cada extremidade das fileiras centrais úteis, compreendendo, no total, uma área útil de 4,0 $\mathrm{m}^{2}$. No caso da semeadura a lanço, manteve-se a parcela com a mesma área útil de $4,0 \mathrm{~m}^{2} \mathrm{e}$ área total de $10,0 \mathrm{~m}^{2}$.

A calagem foi feita de acordo com a análise do solo em todas as parcelas experimentais a lanço, o mesmo sendo verificado com a fosfatagem aplicada na dose de $200 \mathrm{~kg} \cdot \mathrm{ha}^{-1}$ de $\mathrm{P}_{2} \mathrm{O}_{5}$. A adubação básica utilizada foi de $90 \mathrm{~kg} \cdot \mathrm{ha}^{-1}$ de $\mathrm{P}_{2} \mathrm{O}_{5}$ e $60 \mathrm{~kg} \cdot \mathrm{ha}^{-1}$ de $\mathrm{K}_{2} \mathrm{O}$, nas formas de superfosfato simples e cloreto de potássio, sendo realizadas no sulco e a lanço de acordo com a modalidade de semeadura.

À semelhança do que ocorreu com a adubação, também a semeadura nos sulcos foi realizada manualmente, ao passo que, no sistema a lanço, foi distribuída com auxilio de distribuidor de calcário e incorporada com grade leve, em operação conjunta com a adubação.

Aos vinte dias após a emergência, foi realizado o desbaste das plantas de acordo com Rezende et al. (1981) deixando-se, para a semeadura no sulco, 10, 15, 20, 25, 30 e 35 plantas por metro linear e, para a semeadura a lanço, 80, 120, 160, 200, 240 e 280 plantas por $4,0 \mathrm{~m}^{2}$, correspondendo às populações de 200 a 700 mil plantas. ha ${ }^{-1}$, já relatados anteriormente.

Os tratos culturais foram realizados utilizandose, para controle de plantas daninhas, o herbicida Trifluralim, e para o controle de pragas, não foi necessária nenhuma aplicação de inseticida, uma vez que as pragas não atingiram nível de dano econômico.

Por ocasião da colheita, foram avaliadas, na área útil de todas as parcelas, as seguintes características: rendimento de grãos (dados corrigidos para $13 \%$ de umidade e, posteriormente, convertidos para kg.ha ${ }^{-1}$ ), altura da planta e da inserção do primeiro legume (medidas realizadas do colo ao ápice da planta) e a ponta da primeira vagem em dez plantas ao acaso, na fileira útil de cada parcela, expressos em $\mathrm{cm}$, índice de acamamento (escala proposta por Bernard et al. (1965) com notas de 1 a 5, sendo 1 para plantas eretas e 5 para todas as plantas acamadas), e estande final (número de plantas existentes na área útil, por ocasião da colheita).

Os dados foram analisados pelo programa Sisvar ${ }^{\circledR}$ (FERREIRA, 2000), e as médias, comparadas pelo teste de Scott \& Knott, a 5\% de probabilidade.

\section{RESULTADOS E DISCUSSÃO}

De acordo com a Tabela 1, ocorreu efeito significativo em todas as características testadas.

\section{Rendimento de grãos}

O rendimento de grãos foi influenciado significativamente pelos sistemas de semeadura e populações de plantas (Tabela 2). O sistema de semeadura a lanço apresentou aumento significativo no rendimento de grãos, com diferença média entre os dois sistemas de $35,33 \%\left(1.128 \mathrm{~kg} \cdot \mathrm{ha}^{-1}\right)$. Esses resultados eram até certo ponto esperados, pois aquele sistema de semeadura proporciona uma melhor distribuição das plantas por unidade de área, facilitando a penetração da luz e aumentando, conseqüentemente, a taxa assimilatória líquida de $\mathrm{CO}_{2}$, repercutindo em maior produtividade.

Outros pesquisadores demonstraram que altas produtividades nessa cultura são obtidas com a associação de dois caracteres: taxa de assimilação de $\mathrm{CO}_{2}$ elevada e constante, conduzindo à alta produtividade biológica, e alta taxa de translocação dos produtos resultantes da fotossíntese para os grãos, fatores esses que podem ser alcançados com uma boa interceptação de luz e a ausência de estresses hídricos e nutricionais (COSTA e COSTA, 1982). Segundo Wells, citado por Tourino (2000), a produtividade máxima alcançada pela soja é determinada de acordo com a otimização da capacidade da planta em interceptar a radiação solar durante os estádios vegetativo e reprodutivo iniciais.

À semelhança do que ocorreu com o tipo de semeadura, as populações de plantas também alteraram significativamente o rendimento de grãos, com destaque para a utilização de 400, 600 e 700 mil plantas.ha ${ }^{-1}$. Dentro dessas, a melhor opção seria a de usar 400 mil plantas.ha ${ }^{-1}$, o que, além de proporcionar um menor gasto de sementes, foi a que apresentou menor índice de acamamento entre as popu- 
lações que propiciaram maiores produtividades (Tabela 2).

\section{Altura da planta, inserção do primeiro legume, acamamento e estande final}

As características altura da planta e acamamento foram influenciadas significativamente pelas populações e sistemas de semeadura, não se verificando interação entre ambas. $\mathrm{O}$ mesmo não ocorreu em relação à altura da inserção do primeiro legume, que apresentou efeito significativo somente para sistemas de semeadura (Tabela 1).

A semeadura a lanço proporcionou valores médios mais baixos para essas quatro características. Esse sistema pode estar proporcionando uma melhor distribuição de plantas por unidade de área, reduzindo consideravelmente a competição entre as plantas, apesar do aumento da densidade de semeadura, ocasionando melhor interceptação da radiação solar bem como melhor taxa assimilatória de $\mathrm{CO}_{2}$, o que possivelmente favoreceu a presença de plantas de menores portes, com inserção do primeiro legume mais baixa e com índices menores de acamamento. Redução significativa no acamamento, com o aumento da uniformidade de semeadura, foi também observada por Tourino (2000). De acordo com os resultados obtidos, verifica-se uma relação direta entre as características avaliadas, o que foi também constatado por Rezende e Arantes (1982) e Endres (1996), utilizando o sistema de semeadura no sulco.

As diferentes populações utilizadas alteraram significativamente a altura da planta e o índice de acamamento, sendo os valores mais elevados observados, como era de se esperar nas maiores populações (500 a 700 mil plantas.ha $\left.{ }^{-1}\right)$, conforme mostrado na Tabela 2 .

De acordo com Marchiori (1998) e Martins (1998), a redução do espaçamento entre linhas, o aumento da densidade nas linhas e, principalmente, o aumento da competição intra- específica têm sido considerados responsáveis pelo aumento da altura das plantas e do índice de acamamento. Vale ainda ressaltar que, segundo Moore (1991), o maior sombreamento, provocado por densidades elevadas, promove maior altura da planta, em função do aumento da competição por luz pelas plantas adjacentes, favorecendo o acamamento, o que concorda com os resultados obtidos neste trabalho, em que o aumento da população acima de 400 mil plantas.ha ${ }^{-1}$ apresentou maiores alturas de plantas e maiores índices de acamamento.

TABELA 1 - Resumo das análises de variância para os rendimentos de grãos, altura da planta e inserção do $1^{\circ}$ legume, acamamento e estande final obtidos no ensaio sistemas de semeadura e populações, ano agrícola 1991/1992, Jussara, GO.

\begin{tabular}{|c|c|c|c|c|c|c|}
\hline \multirow{3}{*}{$\begin{array}{l}\text { Causa de } \\
\text { Variação }\end{array}$} & \multirow[b]{3}{*}{ G.L } & \multicolumn{5}{|c|}{ Quadrados Médios } \\
\hline & & \multicolumn{3}{|c|}{ Altura } & \multirow[b]{2}{*}{ Acamamento } & \multirow[b]{2}{*}{ Estande Final } \\
\hline & & Grãos & Planta & $\begin{array}{c}\text { Inserção } 1^{0} \\
\text { Legume }\end{array}$ & & \\
\hline Blocos & 2 & 166237,02 & 24,33 & 5,58 & 0,19 & 15,25 \\
\hline Semeadura (S) & 1 & $11455968,44 * *$ & $177,77^{*}$ & $93,44 * *$ & $0,84 * *$ & 66,69 \\
\hline População (P) & 5 & $711613,04^{*}$ & $431,13 * *$ & 9,60 & $0,95 * *$ & $32590,85^{* *}$ \\
\hline S X P & 5 & 324841,31 & 40,44 & 16,84 & 0,09 & 37,29 \\
\hline Resíduo & 22 & 180421,48 & 32,03 & 8,37 & 0,08 & 39,21 \\
\hline $\mathrm{CV}(\%)$ & & 11,31 & 7,50 & 15,64 & 18,78 & 3,52 \\
\hline
\end{tabular}

Ciênc. agrotec., Lavras, v. 28, n. 3, p. 499-504, maio/jun., 2004 
TABELA 2 - Resultados médios de rendimento de grãos, altura da planta e da inserção da $1^{\circ}$ legume, acamamento e estande final, obtidos no ensaio de sistemas de semeadura e populações, ano agrícola 1991/92, Jussara, GO*.

\begin{tabular}{|c|c|c|c|c|c|c|}
\hline \multirow{2}{*}{ Semeadura } & \multirow{2}{*}{$\begin{array}{c}\text { População } \\
\left(\text { mil plantas.ha }^{-1}\right)\end{array}$} & \multirow{2}{*}{$\begin{array}{c}\text { Grãos } \\
\left(\text { kg.hat }^{-1}\right)\end{array}$} & \multicolumn{2}{|c|}{ Altura (cm) } & \multirow{2}{*}{$\begin{array}{l}\text { Acamamento } \\
\quad(1 \text { a } 5)\end{array}$} & \multirow{2}{*}{$\begin{array}{l}\text { Estande final } \\
\qquad\left(4,0 \mathrm{~m}^{2}\right)\end{array}$} \\
\hline & & & Planta & Inserção & & \\
\hline \multirow{6}{*}{ Sulco } & 200 & 3415 & 64 & 18 & 1,00 & 79 \\
\hline & 300 & 2649 & 69 & 21 & 1,33 & 120 \\
\hline & 400 & 3174 & 77 & 22 & 1,50 & 160 \\
\hline & 500 & 2812 & 86 & 21 & 2,00 & 198 \\
\hline & 600 & 3673 & 84 & 18 & 2,00 & 239 \\
\hline & 700 & 3431 & 86 & 21 & 2,17 & 278 \\
\hline \multirow{6}{*}{ Lanço } & 200 & 3742 & 61 & 15 & 1,00 & 79 \\
\hline & 300 & 3782 & 73 & 18 & 1,00 & 120 \\
\hline & 400 & 4599 & 65 & 17 & 1,33 & 158 \\
\hline & 500 & 4509 & 82 & 14 & 1,50 & 200 \\
\hline & 600 & 4651 & 79 & 20 & 1,33 & 227 \\
\hline & 700 & 4640 & 80 & 18 & 2,00 & 278 \\
\hline \multirow{6}{*}{ População } & 200 & $3578 \mathrm{~b}$ & $63 \mathrm{c}$ & 16 & $1,00 \mathrm{c}$ & $79 \quad \mathrm{f}$ \\
\hline & 300 & $3049 \mathrm{~b}$ & $71 \mathrm{~b}$ & 19 & $1,17 \mathrm{c}$ & $120 \mathrm{e}$ \\
\hline & 400 & 3886 a & $71 \mathrm{~b}$ & 19 & $1,42 \mathrm{c}$ & 159 d \\
\hline & 500 & $3660 \mathrm{~b}$ & $84 \mathrm{a}$ & 17 & $1,75 \mathrm{~b}$ & $199 \mathrm{c}$ \\
\hline & 600 & $4162 \mathrm{a}$ & $81 \mathrm{a}$ & 19 & $1,67 \mathrm{~b}$ & $233 \mathrm{~b}$ \\
\hline & 700 & $4035 \mathrm{a}$ & $83 \mathrm{a}$ & 19 & $2,08 \mathrm{a}$ & $278 \mathrm{a}$ \\
\hline Sulco & & $3192 \mathrm{~b}$ & $78 \mathrm{a}$ & $20 \mathrm{a}$ & $1,67 \mathrm{a}$ & $179 \mathrm{a}$ \\
\hline Lanço & & $4320 \mathrm{a}$ & $73 \mathrm{~b}$ & $17 \mathrm{~b}$ & $1,36 \mathrm{~b}$ & $177 \mathrm{a}$ \\
\hline
\end{tabular}

*As médias seguidas pelas mesmas letras nas colunas não diferem estatisticamente entre si, pelo teste de Scott \& Knott, a $5 \%$ de probabilidade.

O estande final não foi influenciado significativamente pelos sistemas de semeadura utilizados (Tabela 1). A utilização do sistema convencional em sulcos não levou a um aumento da mortalidade das plantas, o que poderia ocorrer em função do aumento da competição intra-específica ocasionado pelo aumento das populações estudadas.

\section{CONSIDERAÇÕES GERAIS}

É importante salientar que na semeadura a lanço teriam-se as seguintes operações: adubação e semeadura a lanço e incorporação com grade niveladora, e mais gasto de sementes de até $100 \%$, visto que essas na superfície do solo poderão não germinar, ou ser atacadas por pássaros e formigas, ao passo que, na semeadura convencional, teriase apenas uma única operação, que é a semeadura.

No presente trabalho, não se objetivou verificar custos. Sabe-se, no entanto, que, com o aumento de produtividade obtido no sistema a lanço (1128 $\mathrm{kg} \cdot \mathrm{ha}^{-1}$ ), daria perfeitamente para cobrir as despesas, pois, ao preço atual de $\mathrm{R} \$ 0,80$ o quilo de soja, a receita seria de $\mathrm{R} \$ 902,40$ e os custos de sementes, $\mathrm{R} \$ 2,30$, considerando gasto de $100 \%$ a mais de sementes $(120 \mathrm{~kg}=\mathrm{R} \$ 276,00)$, adubação a lanço (2 horas.ha h $\left.^{-1} \mathrm{x} \$ 25,00=\mathrm{R} \$ 50,00\right)$ mais incorporação das sementes e adubos $\left(2\right.$ horas.ha ${ }^{-1}=$ $\mathrm{R} \$ 50,00)$, que somados ao gasto de sementes atingiria $\mathrm{R} \$ 376,00$ que, diminuídos da receita, ainda daria um saldo positivo de $\mathrm{R} \$ 526,40$. 
É interessante lembrar que no sistema de plantio a lanço não haveria necessidade de adquirir semeadora, que normalmente são máquinas caras e de manutenção mais difícil, o que deveria ser considerado também nos custos.

Novos trabalhos deverão ser realizados, utilizando novas cultivares e dando ênfase aos custos de produção, às implicações de adubação a lanço e, também, à tecnologia de semeadura a lanço, visando a proporcionar aos agricultores uma maior utilização das máquinas de uso constante na fazenda, aliada a um aumento da produtividade.

\section{CONCLUSÕES}

a) A semeadura a lanço proporcionou aumento na produtividade da soja.

b) A utilização da população de 400.000 plantas. ha $^{-1}$ proporcionou ótima produtividade e um menor índice de acamamento.

\section{REFERÊNCIAS BIBLIOGRÁFICAS}

BARNI, N. A.; BERGAMASCHI, H. Técnicas culturais: alguns princípios técnicos para semeadura. In: MIYASAKA, S.; MEDINA, J. C. (Eds.). A soja no Brasil. Campinas: ITAL, 1981. p. 476-480.

BERNARD, R. L.; CHAMBERLAIN, D. W.; LAWRENCE, R. D. (Eds.). Results of the cooperative uniform soybean tests. Washington: USDA, 1965. 134 p.

BRANDÃO, S. S. Cultura do arroz. Viçosa: UREMG, 1968. $194 \mathrm{p}$.

COSTA, J. A.; COSTA, O. M. M. Avaliação de caracteres fisiológicos associados ao rendimento da soja. In: SEMINÁRIO NACIONAL DE PESQUISA DA SOJA, 2., 1981, Brasília. Anais... Londrina: EMBRAPA/ CNPSo, 1982. p. 50-64.

ENDRES, V. C. Espaçamento, densidade e época de semeadura. In: EMPRESA BRASILEIRA DE PESQUISA AGROPECUÁRIA. Soja: recomendações técnicas para Mato Grosso do Sul e Mato Grosso. Dourados, 1996. p. 82-85. (Circular Técnica, 3).

FERREIRA, D. F. Análises estatísticas por meio do Sisvar Windows: versão 4.0. In: REUNIÃO ANUAL DA REGIÃO BRASILEIRA DA SOCIEDADE INTERNACIONAL DE BIOMETRIA, 2000, São Carlos. Anais... São Carlos: RBRAS/UFSCar, 2000.
GUIMARÃES, J. A. P.; ARANTES, N. E. Efeito da semeadura a lanço em soja sobre a produção de grãos e outras características agronômicas. In: Projeto soja: relatório técnico 76/77. Belo horizonte: EPAMIG, 1979. p. 63-66.

MARCHIORI, L. F. S. Desempenho vegetativo e produtivo de três cultivares de soja em cinco densidades populacionais nas épocas normal e safrinha. 1998. 55 f. Dissertação (Mestrado em Fitotecnia) - Escola Superior de Agricultura 'Luís de Queiroz', Piracicaba, 1998.

MARTINS, M. C. Desempenho produtivo de três cultivares de soja em duas épocas de semeadura e em cinco densidades de plantas. 1998. 84 f. Dissertação (Mestrado em Fitotecnia) - Escola Superior de Agricultura ‘Luís de Queiroz', Piracicaba, 1998.

MOORE, S. H. Uniformity of planting effect on soybean population parameters. Crop Science, Madison, v. 31, n. 4, p. 1049-1051, 1991.

PEDROSO, B. A. Densidade e espaçamento entre linhas para arroz (Oryza sativum L.) irrigado. Lavoura Arrozeira, Porto Alegre, v. 42, n. 370, 1987.

REZENDE, A. M. de; ARANTES, N. E. Manejo e tratos culturais da soja. Informe agropecuário, Belo Horizonte, v. 8, n. 94, p. 28-30, 1982.

REZENDE, P. M. de; BUENO, L. C. de; SEDIVAMA, T.; JUNQUEIRA NETTO, A.; LIMA, L. A. de P.; FRAGA, A. C. Épocas de desbaste em experimentos com soja (Glycine max L. Merrill) em diferentes densidades de semeadura. In: SEMINÁRIO NACIONAL DE PESQUISA DE SOJA, 2., 1981, Brasília. Anais... Londrina: EMBRAPA/CNPSoja, 1981. p. 14.

SILVEIRA, G. M. da; BRAGA, N. R.; PEREIRA, J. C. V. N.; BULISANI, E. A. Efeitos de população de plantas na semeadura a lanço de soja. Bragantia, Campinas, v. 42, p. 245-248, 1983.

TOURINO, M. C. C. Arranjo populacional e uniformidade de semeadura na produtividade e outras características da soja [Glycine max (L.) Merrill]. 2000. 139 p. Tese (Doutorado em Fitotecnia) - Universidade Federal de Lavras, Lavras, 2000 . 